\title{
Time travel, hyperspace and Cheshire Cats
}

\author{
Alasdair Richmond ${ }^{1}(\mathbb{D})$
}

Received: 23 September 2016 / Accepted: 17 May 2017 / Published online: 1 June 2017

(C) The Author(s) 2017. This article is an open access publication

\begin{abstract}
H. G. Wells' Time Traveller inhabits uniform Newtonian time. Where relativistic/quantum travelers into the past follow spacetime curvatures, past-bound Wellsians must reverse their direction of travel relative to absolute time. William Grey and Robin Le Poidevin claim reversing Wellsians must overlap with themselves or fade away piecemeal like the Cheshire Cat. Self-overlap is physically impossible but 'Cheshire Cat' fades destroy Wellsians' causal continuity and breed bizarre fusions of traveler-stages with opposed time-directions. However, Wellsians who rotate in higherdimensional space can reverse temporal direction without self-overlap, Cheshire Cats or mereological monstrosities. Alas, hyper-rotation in Newtonian space poses dynamic and biological problems, (e.g. gravitational/electrostatic singularities and catastrophic blood-loss). Controllable and survivable Wellsian travel needs topologically-variable spaces. Newtonian space, not Newtonian time, is Wellsians' real enemy.
\end{abstract}

Keywords Time travel $\cdot$ Dimensionality $\cdot$ Incongruence

\section{Introduction}

Physical travelers into the past must be Gödelians or Wellsians. The former follow spacetime curvatures; the latter reverse temporal direction relative to absolute time. ${ }^{1}$ Newtonian and relativistic physics seemingly forbid Gödelians and Wellsians respectively. Can absolute time admit backward time travel or is curved spacetime required?

\footnotetext{
1 After (respectively) Gödel (1949), Wells (1895)—see also Earman (1995: pp. 160-163).

$凶 \quad$ Alasdair Richmond

A.Richmond@ed.ac.uk

1 Philosophy, University of Edinburgh, Dugald Stewart Building, 3 Charles Street, Edinburgh EH8 9AD, UK
} 
Grey (1999), Le Poidevin (2005) claim reversing extended Wellsians must overlap with themselves or fade away piecemeal like the Cheshire Cat. Either way, travelercontinuity fails and Wellsian reversals are physically impossible.

However, Wellsians have options besides self-overlap or fades, which reveal surprising links between time travel, spatial topology and biology. Pace Grey (1999), Le Poidevin (2005), absolute-time travel is possible if space is sufficiently accommodating. Wellsians can reverse without discontinuity or overlap if they rotate in higher-dimensional space. However, rotation in Newtonian hyperspace is neither (humanly) controllable nor survivable. Controllable, survivable Wellsian travel requires dynamic, variable-topology spaces. Wellsian time can be Newtonian, absolute and uniform; Wellsian space cannot. Wellsian travel requires that space itself be plastic.

\section{Lewisian time travel}

Time travel has been variously defined but David Lewis (1976: p. 145) defined it best:

Inevitably, it involves discrepancy between time and time. Any traveler departs and then arrives at his destination; the time elapsed from departure to arrival (positive, or perhaps zero) is the duration of the journey. But if he is a time traveler, the separation in time between departure and arrival does not equal the duration of the journey.

Discrepancies separate external and personal time. External time is time in a suitablyinclusive reference frame. (E.g. a galaxy's center of mass.) Personal time is travelertime, not a "further temporal dimension, but rather the way in which time is registered by a given object: a heart beating, hair growing, a minute hand moving, a candle burning", (Le Poidevin 2005: p. 339). Travelers' memories, watches, digestion, (etc.) register personal time but none individually constitutes it. (Watch malfunctions or hibernation are not time travel.) Time travel affects everything in travelers' reference frames.

Following Lewis (1976), traveler identity and personal time require correct causal continuity between traveler-stages, and dissolve if inter-stage continuity fails. Whatever their relations to external time, genuine travelers are personal continuants:

For time travel requires personal identity-he who arrives must be the same person who departed. That requires causal continuity, in which causation runs from earlier to later stages in the order of personal time (Lewis 1976: p. 148).

If the usual causal connections underlying traveler-identity and personal time fail en route, the process isn't travel. Stages of genuine travelers are not joined merely by (e.g.) coincidental likenesses, spatiotemporal proximity or accidentally-shared purposes, howsoever close. ${ }^{2}$ Inter-stage qualitative similarity alone cannot make just any stageaggregate into a traveler if correct inter-stage causal links are lacking:

\footnotetext{
2 Nor can they be joined solely by copying — which at least is a causal relationship but not of the right kind. Cf. Lewis (1976: p. 148) on 'counterfeit time travel' achieved via (demon-managed) copying.
} 
... What unites the stages (or segments) of a time traveler is the same sort of mental, or mostly mental, continuity and connectedness that unites anyone else. The only difference is that whereas a common person is connected and continuous with respect to external time, the time traveler is connected and continuous only with respect to his own personal time (Ibid.).

Furthermore, if travelers are normal concrete things, their constitutive links should be spatiotemporally local. Any process that requires spatiotemporally discontinuous inter-stage links arguably does not involve bona fide travel. This papers argues that extended Wellsians cannot maintain correct inter-stage causal links (and hence personal time) unless space has extra dimensions or (preferably) variable structure.

\section{Gödelians and Wellsians}

Wells (1895) has a thoroughly Newtonian background. Newtonian space and time are mutually independent, eternal substances. Newtonian time is absolute and uniformpassing everywhere in the same direction, at the same rate. Newtonian worlds as a whole possess unambiguous time functions and absolute simultaneity, i.e. have a universal 'now'. In relativity, space and time are not independent existents but twin aspects of spacetime. General relativity predicts matter's presence affects spacetime itself and allows time (in effect) to 'curve'. Gödel (1949) describes spacetimes so curved as to allow 'closed timelike curves' (CTCs): journeys that are always (locally) futuredirected yet eventually rendezvous with their own spatiotemporal starting points. Parts of Gödel universes (e.g. galaxies) can have well-defined time-functions but Gödel universes in toto cannot: they have no universal 'now'. (Simultaneity relations cannot be defined for their entirety.) Gödel universes neither begin nor end but simply are: infinite, four-dimensional blocks with strange geometrical 'twists' that let travelers visit any (externally) earlier or later times. Wellsians take peculiar journeys in otherwise conventional universes; Gödelians are otherwise conventional travelers in strangely-structured spacetimes. Wellsians actively go against time's local flow; Gödelians passively follow time's local direction. (Wellsians resemble helicopters in a uniform breeze; Gödelians, balloons in a cyclone.) In effect, Gödelians merely persist in idiosyncratic directions. Gödelians thus don't much resemble time travelers in fiction, who can generally go anywhere in history. Indeed, some (notably Le Poidevin 2005) think Gödelians' relative lack of room for maneuver means they cannot genuinely time-travel. If so, problems for Wellsians doom physical time travel.

Newtonian worlds are temporally well-behaved. Gödel (1949) universes have CTCs through every point. CTCs have well-defined past and future directions locally (in the traveler's vicinity) but not globally (viewed as a whole). Gödelians can re-encounter their own pasts by traveling into their local future. Past and future are only relatively distinct on CTCs, rather as 'up' and 'down' are not absolute distinctions but relative to the Earth's center. (Similarly, clock-faces have well-defined clockwise and anticlockwise directions at every point yet a sufficiently prolonged clockwise journey revisits its starting point.) Reversing direction against external time gives Wellsian travel clear start- and end-points. Such reversals present the problems which are the main focus here. Starts and finishes for Gödelian travel are less clear, as temporal oddi- 

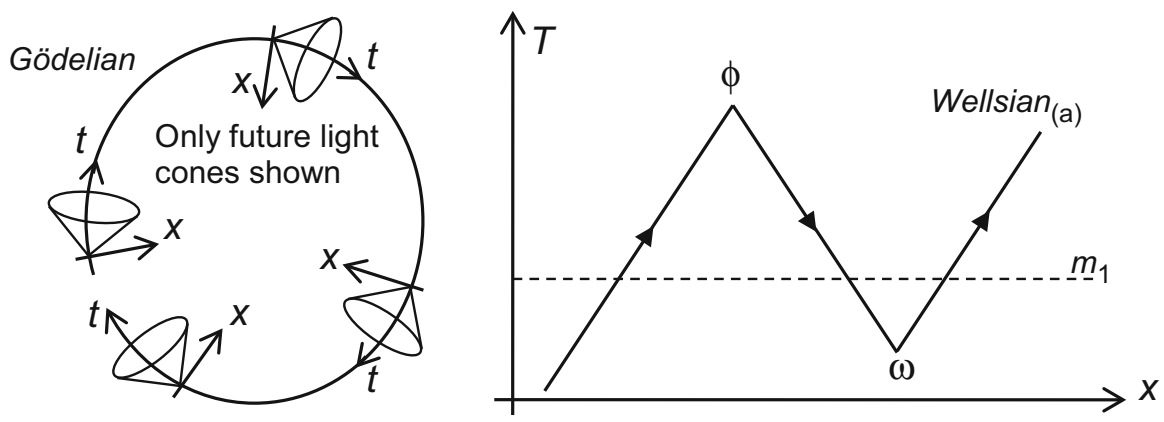

Fig. 1 Gödelian and Wellsian

ties show up only for the whole journey: "In Gödel's space-time the local temporal and causal order will not differ from the one we are familiar with in our world; deviations can only occur for global distances", (Pfarr 1981: p. 1090, emphasis original).

Wells (1895) features no processes recognized by relativity. Relativistic time travel (time dilation or CTCs) requires movement and/or gravitational differences between personal and external reference frames. However, Wells' (1895) Traveller sits at rest (relative to the Earth) with his personal time varying in direction and/or rate of travel relative to all surrounding objects. Everything outside Wells' (1895) machine registers one external time, while the machine enjoys a unique personal time without motion or gravitational differences relative to its surroundings. During backward time-travel, Wells' (1895) Traveller sees everything outside the Machine seemingly go into reverse. Unlike Wellsians, Gödelians see no apparent failures of entropy (or other temporal anomalies) in their immediate extra-vehicular surroundings. Wellsian travel requires locally and globally backward causation; Gödel travel requires only the latter.

Below are depicted one Gödelian and seven Wellsians in various one-dimensional and two-dimensional spaces, ('Linelands' and 'Flatlands' respectively). ${ }^{3}$ All illustrations have one time-dimension. ${ }^{4}$ Wellsian $_{(a)}$ is an unextended (point-like) object which reverses temporal direction twice (first at $\phi$ and then at $\omega$ ) but otherwise persists normally (Fig. 1).

External time increases and personal time decreases $\omega$-to- $\phi$. Each personal moment holds one Wellsian. Each external moment $\omega$-to- $\phi$ (e.g. $m 1$ ) holds three Wellsians, the midmost growing younger as external time increases. Viewed externally, two Wellsians seem to converge on $\phi$ and disappear, while two seemingly appear ex nihilo at $\omega$ and diverge. If these phases form parts of one history, physical continuity (and personal time) must survive $\phi$ and $\omega$-otherwise, they are three separate objects and not one continuant. Wellsian round-trips require both $\phi$-style and $\omega$-style reversals. Wells' (1895) Traveller departs from/returns to external times around $10 \mathrm{am}$ and $7.30 \mathrm{pm}$ respectively on one day early in 1894. Meantime, he spends eight personal days visiting

\footnotetext{
3 After the linear and planar kingdoms in Abbott (1884). See also Rucker (1986: p. 19 ff).

4 Le Poidevin (2005: pp. 340-342) discounts extra temporal dimensions as solutions for double occupancy and follows Lewis (1976: p. 145) in doubting that travel in multi-dimensional time is genuine time travel. Cf. Richmond (2000): pp. 269-270.
} 


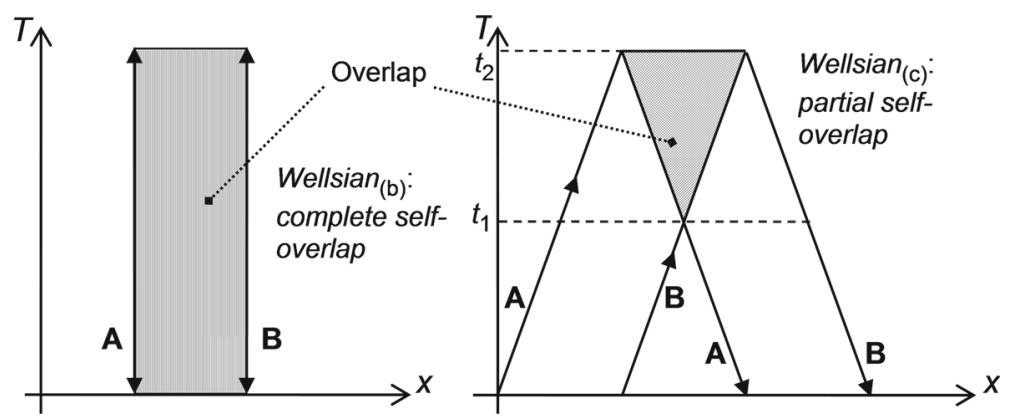

Fig. 2 Double occupancy

$802,701 \mathrm{AD}$ and then c. thirty million AD. He presumably reverses $\phi$-style leaving the future and then $\omega$-style re-entering $1894 .^{5}$

Wellsian reversals seem temporally peculiar but spatially benign—at least for unextended objects. However, extended Wellsians risk overlapping later and earlier selves. What Grey (1999: pp. 60-61) baptizes double occupancy looms pre- $\phi$ and post- $\omega$, with "not one but two machines-one going backwards and the other forwardseach apparently occupying (or attempting to occupy) the same location". Wellsians face identical difficulties at $\phi$-style 'apex-instants' or $\omega$-style 'nadir-instants'-it's changing direction that poses problems. Can extended concrete objects make such transitions?

Dowe (2000: p. 446) suggests reversing Wellsians avoid self-overlap if they also move in space: "To do this sort of time travel you have to take a run up". Passers-by might see a departing Wellsian machine "moving across a field, and ... its reversed later self moving towards it (perhaps an antimatter time machine, perhaps not)", until "the two collide, apparently annihilating both", (ibid., emphasis added). However, as Le Poidevin (2005: p. 344) shows and Fig. 2 illustrates, movement during reversal still leaves some overlap inevitable. (At least movement at finite velocity. Infinite velocity, even if coherent, threatens discontinuous existence or multiple overlapping stages.) Moving is not enough.

Stationary Wellsian $\left(\right.$ b) reverses once at $t_{2}$ so two copies overlap completely at every moment shown. Co-occupancy is more localized and transitory for moving Wellsian $(\mathrm{c})$. The leading and trailing edges of Wellsian $(\mathrm{c})$ are ' $\mathrm{B}$ ' and 'A' respectively. In external time, two of Wellsian $(\mathrm{c})$ first meet at $t_{1}$, when the forward phase's edge B meets the backward phase's edge A. These two Wellsians $(\mathrm{c})$ then progressively overlap until they coincide at $t_{2}$ and vanish thereafter. Wellsians $(\mathrm{b}, \mathrm{c})$ are extended objects which multiply occupy the same spaces for extended periods. If one Wellsian can't exclude another from its space $t_{1}-t_{2}$, is it still concrete at such times? Genuine solutions to double occupancy must at least let Wellsians behave like concrete objects that have continuous histories.

\footnotetext{
5 For probable dates, times and durations of the Traveller's adventures, see Geduld 1987: p. 40, 48 and 94 n. 14. In discarded 1894 drafts, the Traveller overshoots on his journey home, lands first in a prehistoric swamp and then nearly gets shot as a warlock on New Year's Eve 1645, (ibid. pp. 187-188).
} 
Time travelers who are Gödelian, unextended or spatiotemporally discontinuous all evade double occupancy. Likewise, diverse tropes, universals, fields or sortals ${ }^{6}$ can co-occupy. However, "two [concrete] objects of the same kind (persons, chairs, iron spheres)", (Le Poidevin 2005: pp. 336-337) cannot co-occupy. Napoleon and his dress-sense can co-occupy but Napoleon and Wellington cannot, and nor can two Napoleons.

Interestingly, Le Poidevin (2005: p. 350) thinks backward time travel should be something travelers $d o$ (or initiate), and should proceed against time's global direction:

It is, I think, a moot point whether simply following a closed time-like curve in worlds where there is no global earlier-later direction constitutes genuine timetravel. Arguably, time travel is something that, as we might put it, goes against the grain of space-time, rather than simply following it.

If Gödelians are mere slaves of curved spacetimes (with no global time direction to buck), only Wellsians could truly time-travel. (For similar sentiments, see Torretti 1999: p. 79, n. 20.) Even Gödel thought Gödelians weren't strictly time travelers. He thought the possibility of CTCs proved that dynamic time has no objective analogue, therefore our temporal experience tracks only an 'ideal' (apparent or non-objective) time and relativity's 't' co-ordinate is not truly timelike. (See Yourgrau 1999). Hence a dilemma: without global time, Gödelians can't time-travel; Wellsians could (per impossibile) time-travel but spatial problems (e.g. co-occupancy) foil them.

But must time travel be Wellsian? Lewis's (1976) necessary and sufficient condition for time travel, i.e. discrepancy between external and personal time-registers, covers Wellsian and Gödelian alike. Lewis (1976) defines time travel by outcomes, not topologies or methods, and leaves unspecified how discrepancies arise. Pace Gödel, suppose a wormhole takes your (apparent) personal history from 2045 to execution for witchcraft in 1645. If so, being told you hadn't really time-traveled (and/or time is ideal) seems cold comfort. However, Le Poidevin (2005) raises relevant issues even if Gödelians truly time-travel. Gödel universes may lack universal times but other relativistic models permit them. ${ }^{7}$ If future physics restores global times, only Wellsian travel remains. Sections 1-3 surveyed Lewisian time travel, Gödelian/Wellsian differences and double occupancy. Next, Sect. 4 differentiates double occupancy from bilocation and persistence problems. Sections 5-11 outline and refine candidate answers to double occupancy.

\section{Two things double occupancy is not}

(1) Bilocation bilocated time-travelers occupy two distinct places at the same external time and look like two different people, with different personal ages. Bilocation arises if (e.g.) a traveler meets her earlier self. However, double-occupying objects multiply occupy the same place at the same external time. Wellsians or Gödelians can bilocate

\footnotetext{
6 Cf. the co-occupying (but sortally distinct) 'Lumpl' the clay and 'Goliath' the statue in Gibbard (1975).

7 See e.g. Bourne (2006: pp. 160-203). Even Gödel's universe loses its (otherwise ubiquitous) CTCs if modeled in string theory. Cf. Barrow and Dąbrowski (1998).
} 
but only Wellsians double-occupy. Spatially stationary Wellsians co-occupy without bilocation. Time travelers who meet but don't overlap with themselves bilocate without co-occupancy. Wellsian (b) only co-occupies; Wellsian $(\mathrm{c})$ co-occupies and bilocates.

(2) A persistence problem the two chief philosophies of persistence, endurantism and perdurantism, characterize co-occupancy differently but neither evades it, (cf. Le Poidevin 2005: pp. 337-338). For endurantists, persisting objects are wholly present at a time; for perdurantists, objects extend across time. Endurantism implies Wellsians must wholly and simultaneously occupy the same space more than once. Perdurantism implies distinct temporal parts of Wellsians must co-occupy. Either way, each temporal part (or version) is a spatially-extended concretum with its own associated mass and shape.

Note Wellsians' spatial problems are not truly solved by letting Wellsians (e.g.):

- exist discontinuously in space or time,

- become impalpable, abstract or ghostly,

- have identity-conditions supervening on non-causal facts,

- utilize some form of (quasi-Newtonian or quantum) nonlocality,

- have different haecceities for forward- and backward-travelling phases,

- lack well-defined spatial relations with other simultaneously-existing objects,

- bear different (temporal parts of) instantiation relations to identical regions etc.

All such exotica seem ad hoc. Worse, they simply grant (Grey 1999; Le Poidevin 2005) that reversing Wellsians can't behave like classical concrete objects. Wellsians' problems are spatial and only spatial solutions appear herein. To summarize the problem:

- At most one (stage or version of a) concrete object of a given kind can occupy an extended spatial region at a time.

- Reversing Wellsians change temporal direction relative to their surroundings.

- Wellsians are spatiotemporally-continuous extended concrete objects.

Following sections aim to show that these attributes are jointly achievable but that no proper solution to Wellsian problems has appeared hitherto. Sections 5-6 criticize previous solutions. Sections 7-9 explore new, if unsuccessful, solutions. Adapting Sect. 8 'hyperspace' model, Sects. 10, 11 propose a true solution involving altering space itself.

\section{Wells on double occupancy}

Wells himself variously considered co-occupancy-albeit between travelers and other objects, and not between different stages/versions of travelers. Wells (1895) compares time travelers whizzing through history at different 'speeds' to objects crossing space at differing speeds (see Le Poidevin 2005: pp. 338-340). Wellsians who traverse (e.g.) 50 external seconds per personal second travel 50 times 'faster' and make 1/50th of their 'stationary' impression compared to normally-persisting objects, just as bullets make attenuated visual impressions to observers they pass. However, stationary observers see past speeding bullets and not through them, i.e. derive visual impressions primarily 
from whichever background the passing bullets briefly obscure. An observer who comoves with a bullet should see it obscure its background just like any other object. Similarly, anybody shot will find high velocity exacerbates bullets' impact rather than diminishes it. Why should perceptual attenuation make objects less present at places they occupy? Physical presence is the problem, not perception of it.

Wells' (1894) serial version of The Time Machine at least treats co-occupancy physically as well as perceptually. Once Wells' (1894) 'Philosophical Inventor' has described traveling to and from A.D. 12,203, one of his auditors asks why no future people noticed him while he occupied the same (relative) place for millennia. At first, the Inventor waxes analogical in reply, invoking perception like his (1895) successor:

Suppose, for instance, you put some red pigment on a sheet of paper, it excites a certain visual sensation, does it not? Now halve the amount of pigment, the sensation diminishes. Halve it again, the impression of red is still weaker. Continue the process. Clearly there will always be some pigment left, but a time will speedily arrive when the eye will refuse to follow the dilution, when the stimulus will be insufficient to excite the sensation of red. The presentation of red pigment to the senses is then said to be "below the threshold." Similarly my rapid passage through time, traversing a day in a minute fraction of a second, diluted the stimulus I offered to the perception of these excellent people of futurity ... (Geduld 1987: p. 159)

Note Wells' (1894) Inventor glosses machine 'speed' using personal/external time: in 'rapid passage', fractional personal seconds encompass external days. Conceding the perceptual point (maybe prematurely), the questioner then raises physical cooccupancy:

I suppose while you were slipping thus invisibly through the ages, people walked about in the space you occupied. They may have pulled down your house about your head and built a brick wall in your substance. And yet, you know, it is generally believed that two bodies cannot occupy the same space (Geduld 1987: p. 159).

Here, the Philosophical Inventor replies with a non sequitur about molecular diffusion:

Don't you know that every body, solid, liquid, or gaseous, is made up of molecules with empty spaces between them? That leaves plenty of room to slip through a brick wall, if you only have momentum enough. A slight rise of temperature would be all one would notice and of course if the wall lasted too long and the warmth became uncomfortable one could shift the apparatus a little in space and get out of the inconvenience (Ibid.).

But varying personal/external time shouldn't mitigate spatial co-occupancy. Why can't any solids interpenetrate given sufficient relative momentum? Anyway, gasmolecules slipping through membranes move relative to whatever they permeate; Wells' machines hold stationary relative to any co-occupied objects. Interpenetration is nothing to the purpose: gaseous diffusion never involves multiple extended concreta simultaneously occupying numerically the same space. (Anyway, as Wells' $1894 / 95$ travelers can see external events, neither is really impalpable while traveling.) 


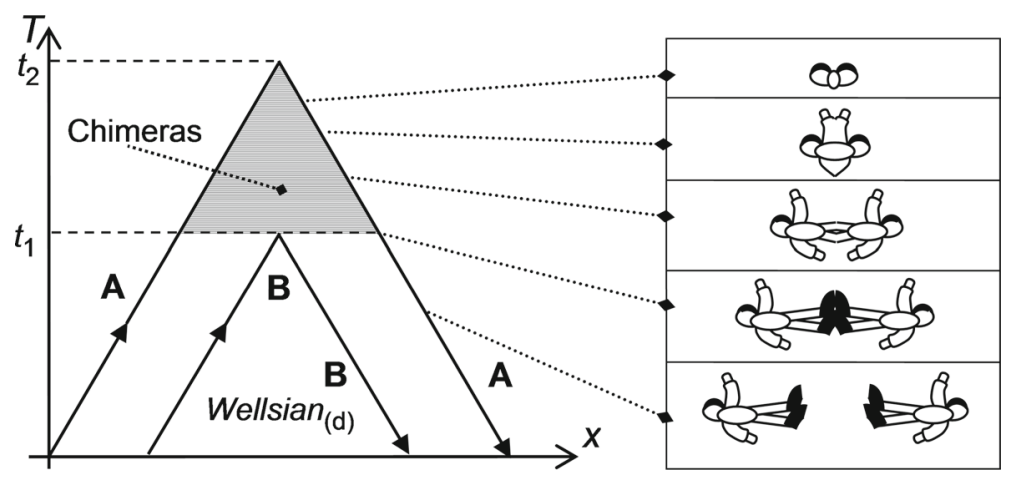

Fig. 3 Cheshire Cat

While Wells' attempts fail, other options have been proposed. Section 6 surveys Le Poidevin's (2005) suggestions, whereby reversing Wellsians perforce disintegrate (and re-integrate) en route. While Le Poidevin (2005) is clear that such solutions themselves fail, his critique is instructive.

\section{Cheshire Cats and chimeras}

Le Poidevin (2005: p. 345 ff.) suggests Wellsians can avoid self-overlap by departing 'Cheshire Cat' fashion, each part having a separate departure-time. Wellsian $(\mathrm{d})$ departs piecemeal: edge B leaves at $t_{1}$ and edge $\mathrm{A}$ at $t_{2}$. Self-overlap is avoided because each part reverses at a different apex-instant. However, the need to maintain continuity makes travelers' forward and backward phases peculiarly contiguous. Henceforth fusions of contiguous temporally-opposed masses are 'chimeras' and twoheaded chimeras 'Pushmi-Pullyus' ${ }^{8}$ Above right, a reversing astronaut's two phases meet toe-to-toe at $t_{1}$ and fuse without overlap. Nearing $t_{2}$, our astronaut's remains have dwindled to two contiguous copies of a scalp. This twin-scalped chimera diminishes until vanishing at $t_{2}$ (Fig. 3).

Chimeras and Pushmi-Pullyus can last arbitrarily long, depending on their parent phases' size and velocity. Traveler-orientation determines chimeras' shape. (Their phases needn't be mirror-images, e.g. if travelers rotate while reversing.) Head-first travelers vanish feet-last, their headless chimeras "too horrible to contemplate", (Le Poidevin 2005: p. 346). A four-limbed, back-first, traveler yields four chimeras-one per limb. Whither the traveler in this four-way fission? That traveler identity could supervene purely on said traveler's scalp seems implausible but still more so is a traveler surviving for unspecified periods as four spatially-disjoint objects, (none of them containing a brain). Can physical travelers who lack brains have psychological states?

Wellsian $_{(\mathrm{c})}$ departs in one piece at $t_{2}$. Wellsian (d) has no clear departure-time: its front (B) reverses at $t_{1}$ and its back (A) at $t_{2}$. Wellsian (d) is all gone by $t_{2}$ but $t_{2}$ isn't

\footnotetext{
8 After the antelope with a head at each end in Lofting (1920). Dramatizations often portray the PushmiPullyu as a bicephalous llama.
} 


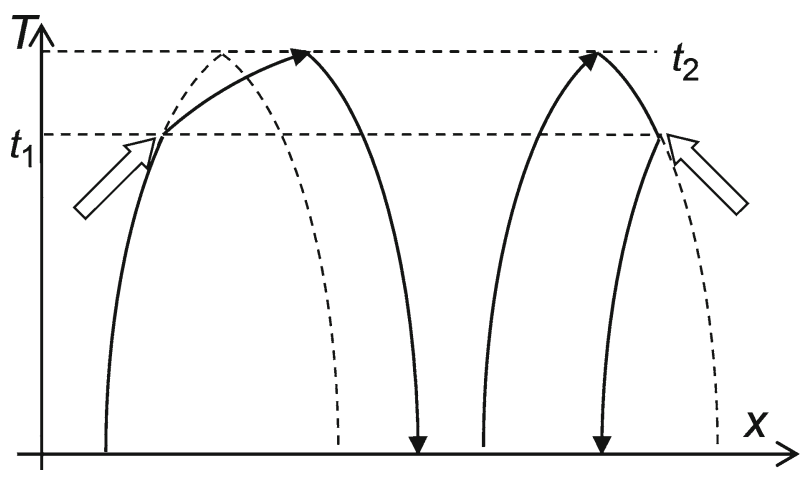

Fig. 4 'Push' aymmetry

the departure-time. Continuity and identity fail if Wellsians and their spatial parts cannot attend all external times in their careers: "How can something continue to exist if there are (external) times when only a spatial part of it does so?", (Le Poidevin 2005: p. 345). Cheshire Cat fades destroy travelers and are not mere interludes in their careers. 'Cheshire Cat' solutions must let all a Wellsian's spatial parts visit all times in its career and retain normal causal powers. Travel shouldn't oblige travelers to shed themselves.

Co-occupancy, Cheshire Cats and chimeras all imperil personal time. For the Januslike Pushmi-Pullyu at $t_{1}, t_{2}$ is in its left head's personal future but its right head's personal past-it also registers $t_{1}$ twice in experience (once per head) and once in memory (right head only). However, if Cheshire Cats destroy traveler-identity, personal time fails for Pushmi-Pullyus and memories don't survive head-to-head.

Chimeras have problematic personal time even if causal links survive Cheshire Cat fades. Figure 4 left-hand traveler is pushed rightward at $t_{1}$. All its personally subsequent stages are displaced rightward, whether externally later or earlier. Figure 4 right-hand traveler is pushed leftward at $t_{1}$. This push affects only externally-earlier stages with $t_{1}$ twice in their personal past. Leftward pushing has direct effects externally later and earlier; rightward pushing has direct effects only externally earlier. When the leftmost traveler revisits $t_{1}$, where it re-intersects $t_{1}$ is largely determined by influences exerted at that very (external) time. Even if causal continuity survives reversal, chimeras allow effectively instantaneous causal transmission along a timeslice and hence their inter-stage causal connections aren't linearly ordered even in personal time, (cf. Le Poidevin 2005, p. 348). So phases of Cheshire Cats can't comprise genuine travelers because they lack correct inter-stage links. However, chimeras' contiguous masses can't comprise genuine travelers either because of their surfeit of inter-stage links. Again, traveler-identity requires that "causation runs from earlier to later stages in the order of personal time," (Lewis 1976: p. 148).

Mereological universalists ${ }^{9}$ think that any sum of temporal parts composes an object but yet insist that genuinely salient continuants only fall under certain sortals (e.g.

\footnotetext{
9 E.g. "I claim that mereological composition is unrestricted: any old class of things has a mereological sum”, Lewis (1986: p. 211).
} 
'person') and embody correct causal links. Mereological universalism alone can't save Wellsians because chimeras' salience-criteria are problematic and their personal time ill-ordered. Fusions of causally-disjoint stages are not persons even if made of persons. The Cheshire Cat diachronic question is 'When does this thing depart?'; the Pushmi-Pullyu synchronic questions are 'What is this thing?' and 'Is this one thing?'. Also, electrostatic problems loom as chimera-phases get arbitrarily close together:

How close do the series get to each other? The answer is that they actually make contact, before converging on a single temporal part. This is genuine contact, not the mere close proximity that passes for contact in everyday situations. The subatomic structure of matter imposes limits on how close atoms can get to each other. But [a reversing Wellsian] transcends those limits (Le Poidevin 2005: p. 349).

A reversing hydrogen atom would see its two phases' nuclei fuse into a single proton while their electronic orbits overlap. Discrete (i.e. only finitely-decomposable) space might alleviate unphysical proximity but Newtonian space is supposed to be continuous. 'Forward' charged particles should repel their own 'backward' counterparts if they retain constant charge through reversal. Coulomb's inverse-square law implies arbitrarily-small separations of like charges require unbounded energy: their mutual repulsion blows up arbitrarily as their separation approaches zero. The closer they get, the harder getting them any closer becomes and the more readily they spring apart. Fusing like charges strictly governed by Coulomb's law is physically prohibitive.

What if a reversing particle's phases have opposite charges? Famously, WheelerFeynman theory says "positrons can be represented as electrons with proper time reversed relative to true time". ${ }^{10}$ If so, the two phases' charged particles attract their opposite numbers but their backward-traveling phases are antimatter. In which case, oppositely-directed phases cannot form chimeras without mutual annihilation. (As Grey (1999: p. 62) notes, Wheeler-Feynman reversals should be highly energetic.) An electrostatic dilemma: reversing constant charges requires unbounded energy but reversing opposed charges threatens mutual annihilation. Physics aside, logic forbids mutual annihilation between an object's earlier and later phases. An earlier phase can destroy a later without inconsistency. However, a later phase destroying an earlier yields a 'Grandfather' (strictly 'Autoinfanticide') Paradox. At least WheelerFeynman theory suggests how Wellsian reversal might occur: if backward-matter is antimatter, inverting a particle's charge should induce Wellsian reversal. However, it remains unclear what could switch charges or reverse uncharged particles. (Section 10 revisits and addresses Wheeler-Feynman issues for Wellsians.) Clearly, appeals to motion, perception, interpenetration or disintegration alone cannot solve double occupancy. Section 7 considers new 'solutions', wherein travelers can radically change shape.

\footnotetext{
10 Feynman (1949): p. 753, n. 7. What Feynman calls 'proper' and 'true' time are effectively Lewisian personal and external time respectively.
} 
Fig. 5 Singularity (T/x plane)
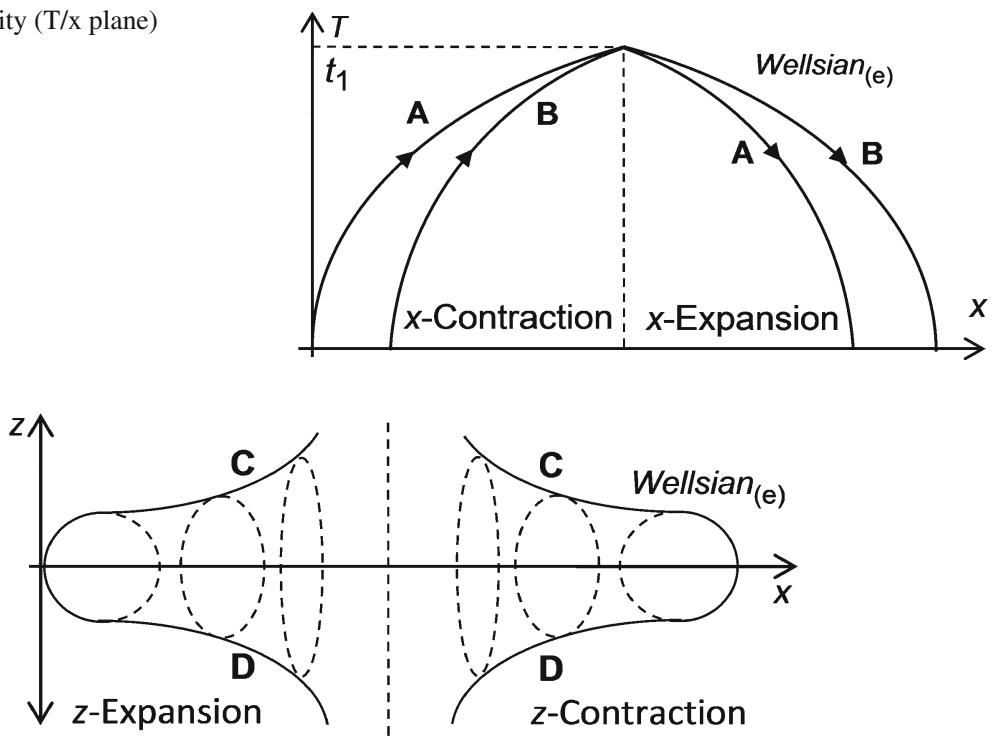

Fig. 6 Singularity (x-plane)

\section{Singularity Wellsians}

Sections 2-6 suggest some lessons: To avoid co-occupancy and chimeras, Wellsians' stages must never overlap or form contiguous masses. To avoid Cheshire Cats, all a Wellsian's spatial parts should be able to visit all external times in its career. Sections 7-11 consider new therapies for co-occupancy, Cheshire Cats and chimeras. Those of Sect. 7 involve radical shape-changes and arbitrarily-dense matter. Those of Sections 8-11 allow constant shape and density but require extra spatial dimensions $($ Sects. 8, 9) or variable topology (Sects. 10,11). Wellsians $(\mathrm{a}-\mathrm{c})$ reverse intact while Wellsian $_{(\mathrm{d})}$ decomposes into particles. Spatially two-dimensional Wellsian $(\mathrm{e})$ begins circular but drastically changes shape: its $x$-extremities (A, B) get arbitrarily close and its $z$-extremities $(\mathrm{C}, \mathrm{D})$ arbitrarily separated at $t_{1}$. Wellsian $(\mathrm{e})$ 's cross-section is ill-defined at $t_{1}$ but otherwise constant (Figs. 5, 6).

All of Wellsian $_{(\mathrm{e})}$ registers completely at least once on every global timeslice. Its phases also only meet along a line-so no overlapping parts, Cheshire Cat fades or chimeras.

Problem solved? Alas, no: consider what happens at $t_{1}$. Completely avoiding overlap while keeping cross-sectional area constant drives Wellsian $_{(\mathrm{e})}$ towards nil length and unbounded breadth at $t_{1}$ : Wellsian (e) 's shrinking towards nil $x$-length must compensatingly drive it towards unbounded size in the $y$-direction. So Wellsian $(f)$ must go from finite area and breadth to (effectively) zero area and infinite breadth, and back again, in finite time. Since Newtonian physics sets no theoretical limit on how fast objects can travel, at least Newtonian spacetimes permit the arbitrarily-large velocities such 'Singularity' Wellsians need. However, letting parts of Singularity Wellsians proceed to (and from) arbitrary distances arbitrarily fast also needs remarkable scarcity 
of other objects around $t_{1}$ if catastrophic collisions are to be avoided. If Wellsian $(\mathrm{f})$ 's cross-sectional area can vary arbitrarily, then at least its z-extremities can be finitely far apart traveling through $t_{1}$. Even so, Wellsian(f) still hits a linear singularity of zero area and unbounded density at $t_{1}$.

One help for 'Singularity' solutions is that Newtonian physics allows arbitrarilydivisible matter. However, can objects survive being compressed to infinitesimal length? Real matter has sharply differentiated structure at sub-atomic, atomic and molecular levels. 'Infinitesimal' stages of Singularity Wellsians must have components arbitrarily smaller than (e.g.) any electron. If no physical structure survives reversal, causal continuity fails and Wellsian $($ f) 's forward/backward phases are distinct continuants. Also, as Singularity Wellsians become arbitrarily dense around $t_{1}$, their resulting runaway gravitation should make them 'dark stars': classical bodies whose gravitation is so intense no physical object traveling slower than light can escape from their vicinity. ${ }^{11}$ Such Wellsians would be invisible to outside observers when reversing but have large gravitational effects on their surroundings. A dilemma looms: restoring 'dark star' travelers to finite density/size after reversal seems difficult even if their causal continuity survives the 'Singularity', but double occupancy recurs if any finite $x$-extension survives through $t_{1}$. Neither option makes 'Singularities' survivable.

Coulomb's law poses problems here too: arbitrarily-compressing multiple like charges requires unbounded energy. (Although electrostatic repulsion might explain how arbitrarily-compressed travelers regain normal size post-reversal.) Preserving Wellsians' causal continuity requires more than spatiotemporal proximity and continuity for their parts. (Parts of exploding objects retain continuous trajectories yet being exploded destroys objects nonetheless.) Bouncing through $(n-1)$-dimensional singularities would destroy $n$-dimensional Wellsians. Cheshire Cat solutions cannot merely let each Wellsian-part have a continuous trajectory; Wellsians (and their parts) must also retain:

(1) Presence on all global times in their histories,

(2) Finite size and density,

(3) Continuous trajectories,

(4) Constant shape.

Singularity Wellsians can observe (1) while their parts can observe (1) and (3). But neither Singularity Wellsians nor their parts can observe (2) or (4). 'Singularity' solutions fail. Section 8 considers a better option: allowing Wellsian space extra dimensions.

\section{Hyper-rotation}

While unsuccessful, Singularity solutions have instructive features, e.g. phases meeting along a frontier with one fewer dimension than their surrounding space. Wellsian $_{(\mathrm{d})}$ 's leading edge is B in forward travel but A in backward. So Wellsian $(\mathrm{d})$ also changes chirality; its phases incongruent counterparts. Double-occupancy and Singularity Wellsians maintain congruency but Cheshire Cats resemble another Well-

11 Dark stars were first discussed in Reverend John Michell's letter to Henry Cavendish, see Michell (1784). 


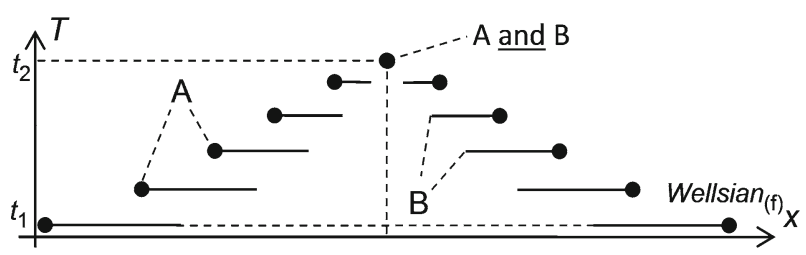

Fig. 7 Hyper-rotation in T/x plane

sian protagonist, that of Wells' (1896) 'The Plattner Story'. ${ }^{12}$ A mysterious explosive blows schoolmaster Plattner into another realm, where he spends 9 days before dropping back into earthly life. On return, Plattner's body has seemingly swapped left and right sides. As rotation in $(n+)$-dimensions makes orientable $n$-dimensional shapes non-orientable, Wells' (1896) narrator wonders if Plattner has been rotated in fourdimensional space.

Abbott's (1884) two-dimensional protagonist, 'A. Square', visits one-dimensional Lineland in a dream. A. Square imagines trying to persuade Lineland's King that Flatland exists by speaking to His Linear Majesty from His insides. Lindgren and Banchoff (2010: p. 135) suggest a better demonstration, i.e. A. Square 'Plattnerizing' Lineland's King by rotating His Linear Majesty through $180^{\circ}$ in Flatland. (Lineland's King has two voices, bass and tenor, one at each end. Hyper-rotating the King should make His tenor voice emanate whence His bass voice came and vice versa.)

If Cheshire Cat phases form a single continuant (and so merely change chirality rather than lose identity), their constituent causal connections must survive. Plattner's alteration involves only spatial movement, i.e. no time travel occurs and no instant holds multiple Plattners or Plattner-stages. Plattner's chirality alters but his causal continuity survives. What if Wellsians can also rotate Plattner-fashion? Wellsian $(f)$ from a Newtonian 'Lineland' reverses in time while rotating in $(x-z)$ Flatland 'hyperspace'. ${ }^{13}$ Wellsian $_{(\mathrm{f})}$ rotates through $90^{\circ} t_{1}$-to- $t_{2}$ and (personally later) rotates another $90^{\circ} t_{2}$-to- $t_{1}$. At $t_{2}$, Wellsian (f) is instantaneously orthogonal to Lineland. Hyper-rotation also 'Plattnerizes' $W_{\text {ellsian }}(\mathrm{f})$, making forward and backward phases into enantiomorphic counterparts (Figs. 7,8).

$\mathrm{Wellsian}_{(\mathrm{f})}$ starts rotating at $t_{1}$ but begins backward travel (en bloc) at $t_{2}$. As rotation begins, Wellsian (f) seems to dwindle to a point, apparently leaving only a dimensionless cross-section of itself in Lineland. (Likewise hyper-rotating Flatlanders should present linear cross-sections to Flatland observers and hyper-rotating threedimensional travelers in turn should leave planar cross-sections in Spaceland.) All

\footnotetext{
12 Discussed in Lindgren and Banchoff (2010: p. 153). Lindgren and Banchoff (2010: p. 171) also discuss Abbott (1884) as a source for Wells' fourth-dimensional interests. For more on Plattner and time, see Richmond (2000).

13 While this paper was in progress, a very interesting, rather different, set of spatial solutions to double occupancy (et al.) were proposed in Bernstein (2015), especially 3.1 ('Personal Space and External Space', pp. 165-166). One difference between this paper and Bernstein (2015) is the focus herein on how much of Newtonian space can be preserved in allowing Wellsian reversals; if the arguments herein work, Bernstein's (2015) 'personal spaces' must have certain features (e.g. be dynamic and non-uniform) if Wellsians' spatial problems are not to resurface in personal space. While nothing herein aims to criticise Bernstein (2015), this paper might help explore how such 'personal spaces' could (or should) be structured.
} 


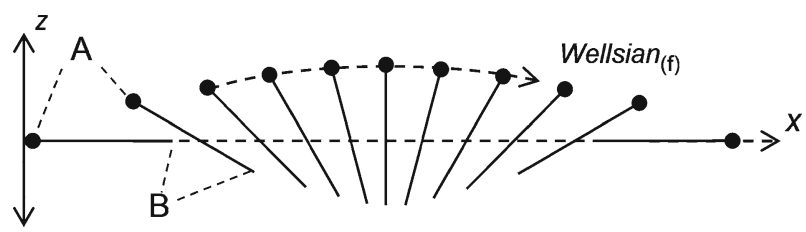

Fig. 8 Hyper-rotation in $\mathrm{x} / \mathrm{z}$ plane

such hyper-rotating travelers would appear to lose a spatial dimension when viewed from within their native spaces.

However, unlike Singularity Wellsians' genuine dimension-loss, these snap-fades and dimensional losses are only apparent. In $(x-z)$ Flatland, Wellsian $(f)$ retains constant extension and shape. Wellsian (f) has nil $x$-extension when its phases meet at $t_{2}$ so no parts overlap and yet all its spatial parts register (in their correct relative places) on every global time-slice. A rotational Wellsian's stage-sum has one more spatial dimension than any individual stage; $n$-dimensional Wellsians forming $(n+)$ dimensional stage-aggregates. Each stage has a unique spatiotemporal location without co-occupancy, Cheshire Cats, chimeras, shape-changes or runaway density. Rotating Wellsians change chirality when reversing but otherwise maintain continuity. Hyperrotation meets all four desiderata for Cheshire Cat solutions while avoiding unphysical proximity (and electron overlap) without finitely-sized spatial atoms. It isn't clear how electromagnetic fields from an $n$-dimensional object would propagate if that object were translated into $(n+)$-dimensional space. However, at least if $n$-dimensional charges generate $n$-dimensional charge-fronts and Wellsians' phases meet obliquely in $(n+)$-space, then their phases don't overlap 'field-to-field'. (Consider how two planes that meet obliquely in three dimensions will overlap only at a line and not at a surface.) Hyper-rotating travelers' phases will only meet at apex-instants and along an axis where they are themselves extensionless. Apex-instants hold only one travelerstage and hence threaten no multiple contiguous or overlapping stages. Hyper-rotation allows Wellsians sufficient physical continuity for their personal time to be defined without ambiguity or circularity.

Apex instants have ancestors and (distinct) successors at externally-earlier times. But what temporal directions have travelers at apex instants? Presumably, forward or backward yet there seems no basis to assign either. Does hyper-rotation make a single traveler-stage (instantaneously) temporally bidirectional and dissolve double occupancy only to yield paradox? Not necessarily: apex instants can be finessed by adapting 'at-at' theories of motion often invoked to address Zeno's 'Arrow' and 'Stadium'. 'At-at' theories of motion can treat instantaneous velocities as ill-defined or as limit-values; instantaneous temporal directions could be treated likewise.

Wellsians approaching apex instants occupy certain places at certain times. Their personal and external time increase during approach. They then occupy certain places at apex instants. Personally thereafter (but earlier externally), they occupy other places. If travelers lose well-defined time-directions at instants where they also cease bilocation, this isn't necessarily problematic. If Wellsians exhibit neither bilocation nor chimeras at apex instants, where might a physical basis for attributing opposed timedirections reside? Perhaps reversing Wellsians have well-defined time-directions over 
any finite period but lack time-direction at an (apex or other) instant. Regardless of what happens at apex-instants, co-occupancy and chimeras yield multiple phases with opposed time-directions which (respectively) overlap or fuse for extended periods. 'At-at' views of time-direction alone won't banish double occupancy. Even if (e.g.) Wellsian $_{(\mathrm{c})}$ has one temporally directionless stage at $t_{2}$, its phases protractedly overlap approaching $t_{2}$.

Hyper-rotation means Wellsians' forward and backward phases join via a single spatially-complete phase which instantaneously lacks time-direction. (Nowhere do oppositely-oriented phases overlap or fuse over extended periods.) If time is continuous, there will be no well-defined last instant where two stages exist but apex instants can still be defined, i.e. as instants whose causal ancestors and (distinct) causal successors occupy numerically the same externally earlier times. Apex instants are junctures between externally-increasing and externally-decreasing times, visited in that personal order; nadir instants are junctures between externally-decreasing and externally-increasing times, visited in that personal order. The best joint spatial therapy thus far for co-occupancy, Cheshire Cats and chimeras involves reversing Wellsians simultaneously moving and rotating out of local space. Is Wellsian travel saved? Well, progress has been made but, as Sect. 9 shows, hyper-rotation seems little real help if (e.g.) rotation is uncontrollable and/or only available to non-living things. Only Sects. 10, 11 truly dissolve Wellsians' problems.

\section{Dynamic and biological hyper-rotation problems}

Even if hyper-rotation avoids co-occupancy and chimeras, new problems arise. How might $n$-dimensional objects rotate/translate into $(n+)$-dimensional space? In Wells (1896), the explosion of a mysterious powder triggers Plattner's rotation but how a (presumably) 3-space explosive could rotate Plattner through one more dimension than the explosive itself enjoys seems unclear. If the explosive changes Plattner's momentum orthogonally to the direction of any exerted force, it violates Newton's second law. But if the explosive is spatially four-dimensional, Plattner can only handle an infinitesimal cross-section of its true hyperspatial extent. It's also unclear how the explosive makes Plattner rotate, since any hyperspatial blast-front centered in, and propagated through, 3-space would push Plattner through his center of gravity. Maybe Plattner's transition is dynamically possible if the explosive impinges on him obliquely from outside 3-space. Perhaps something four-dimensional 'peels' Plattner from 3space, spins him through $180^{\circ}$ in 3-space about an area (i.e. not an axis) internal to him and then drops him back into 3-space as his own earlier self's enantiomorph. However, Platter (like any 3-space creature) seems powerless to initiate or control 'hyperspatial' (4-space) journeys.

Likewise in Abbott (1884), rather than lower-dimensional spaces pushing their occupants forth into hyperspace, higher-dimensional creatures reach down and abstract creatures from lower-dimensional spaces. (A visiting Sphere translates Abbot's Square into 3-dimensional Spaceland.) If hyper-rotation requires help from higherdimensional life, controllable travel for $n$-dimensional Wellsians requires not only the existence of, but communications with, amenable $(n+)$-dimensional beings. 
Spacelanders could assist Flatlanders (or Linelanders), and Flatlanders could assist Linelanders, but no realm can facilitate Wellsian travel for its indigenous life unassisted.

Spaces with $(n>3)$ are usually thought possible. However, James van Cleve disagrees: "for my part, the intuition that three mutually perpendicular lines leave no room for a fourth, or that a sphere intercepts all paths from inside to outside, is as compelling as the intuition that red excludes blue from the same surface". ${ }^{14}$ If so, the maximally-dimensioned possible Wellsians are Flatlanders and humans are too 'deep' for hyper-rotation. Even allowing $(n>3)$ spaces, maybe only $(n=3)$ spaces permit life, e.g. if $(n \neq 3)$ spaces forbid functional nervous systems, digestive tracts or stable planetary orbits. (Cf. Whitrow 1955.) If so, no $(n \neq 3)$ life can help 3-space Wellsians or receive their help.

How might $n$-dimensional objects interact in $(n+)$-dimensional spaces? Perhaps $n$ dimensional objects seem insubstantial to $(n+)$-dimensional ones: "If the Flatlanders are truly two-dimensional, with no thickness at all, then they will be as immaterial as shadows or patches of light", (Rucker 1986: p. 19). However, if $n$-dimensional objects retain finite mass in $(n+)$-dimensions, $n$-dimensional bodies might strike other objects like perfectly sharp blades or prove insusceptible to manipulation against a fixed $(n+)$ dimensional spatial background. Rather than shadows, finite-mass Flatlanders might resemble planar 'dark stars' in Spaceland. Likewise, Plattner or A. Square might grievously slice or puncture anything they strike during their hyperspatial sojourns.

Hyper-rotating humans poses biological problems too. Enclosed ( $n$ )-dimensional cavities become open in $(n+)$-dimensions. Hyper-rotating any enclosing vessel while it translates whisks away the enclosure. Forces rotating human bodies in 4-space must act orthogonally to (e.g.) van der Waals forces, contact forces and surface-adhesion forces that normally hold those bodies' fluid contents in. Travelers' blood will tend to retain its original state of motion and thus escape as all but a cross-section of its containing vessels gets rotated into hyperspace. Hyper-rotated travelers would presumably die if they shed most, if not all, of their blood, breath, lymph, cerebrospinal fluid etc. 'Plattner' hyper-rotation relative to (or out of) local space, i.e. travelers' immediate surroundings, seems highly injurious to anything like anthropomorphic life. (Assuming inter-molecular bonds cannot be extended at will, so each traveler effectively becomes one giant molecule. However, this too would be disastrous for life as we know it: a body formed of one giant molecule would be ill-equipped to absorb nutrients and lose wastes.)

Could $n$-dimensional Wellsians avoid fluid-losses by traveling shielded by other $n$ dimensional objects? Alas, keeping $n$-dimensional bodies completely fluid-tight using $n$-dimensional shielding seems a tall order, since the bodies and shields seem obliged to be perfectly contiguous, i.e. with no finite-sized gaps at all. (Imagine fluid-filled Flatlanders rotating while sandwiched between two planar shields.) In any event, shielding necessarily interposes other solid objects between traveler-phases, yielding another kind of discontinuity. Hyper-rotation might be survivable for 'solid-state' Wellsians

14 van Cleve (1987): p. 64. Lindgren and Banchoff (2010: p. 232) claim Aristotle's On The Heavens (268 ab) implies no $(n>3)$ space is possible by denying "the possibility of extending the derivation sequence beyond the third dimension". 
lacking fluid-filled cavities or Wellsians who upload their conscious functions onto non-biological vehicles before rotation and retrieve them afterwards. (Maybe Wellsians could rotate while cryogenically frozen-although freezing must completely immobilize all their fluid contents, gaseous and liquid.) Even allowing ( $n>3)$ spaces (pace van Cleve 1987), hyper-rotated humans seem doomed to die and leave messy residues behind. Section 10. shows how hyper-rotation can be controllable and survivable, inspired by William Kingdon Clifford (1886: p. 224 ff.) on spatial structure. Only here are double occupancy and Cheshire Cat problems dissolved, and Wellsian travel vindicated.

\section{Cliffordian and neo-Cliffordian space}

Cavity-filled $n$-dimensional objects open catastrophically if rotated/translated in flat $(n+)$-dimensional spaces. What about more complex topologies? Suitable topologies might let Wellsians take their local $n$-dimensional surroundings with them. Suppose space is not uniform and immutable as Newton assumed but flexible, much as 'rubber sheet' models of gravitation depict spacetime.

Newton accepted only separate, flat space and time. General relativity postulates curved spacetime. However, William Kingdon Clifford (1845-1879) imagined locallycurved spaces, intermediate between Newtonian space and Einsteinian spacetime. Specifically, Clifford considered the dynamic implications of spatial curvature varying across places and times. Such spaces can also solve Wellsians' problems. Inspired by Riemann, Clifford wondered if local spatial curvatures cause apparent force phenomena. Perhaps we treat "merely as physical variations effects which are really due to changes in the curvature of our space; [perhaps] some or all of those causes which we term physical may not be due to the geometrical construction of our space", (Clifford 1886: p. 224). Cliffordian space and matter relate asymmetrically: topology dictates matter-distribution but not vice versa. Adapting John Wheeler's summary of general relativity: Cliffordian space tells matter how to move, but matter cannot tell Cliffordian space how to curve. ${ }^{15}$

Clifford also postulated that "degree of curvature may change as a whole with the time [and] change of curvature might produce in space a succession of apparent physical changes" (1886: p. 225). If $n$-dimensional space can bulge like a rubber sheet, portions of it can (effectively) rotate in $(n+)$-dimensional space, carrying traveler phases along with them so they meet without overlapping. Such Wellsians wouldn't rotate relative to local space but instead travel with local space as it 'rotates'. Wellsian $_{(\mathrm{g})}$ 's Lineland can form branch loops that smoothly diverge from, and reconnect with, their parent space.

\footnotetext{
15 Russell rejected variably-curved (e.g. Clifford) space as "logically unsound and impossible to know, and therefore to be condemned à priori", (1897), (1996 edition: p. 118). Later Russell ruefully admitted "The geometry in Einstein's General Theory of Relativity is such as I had declared to be impossible", (Russell 1959), (1997 edition: p. 31). For Russell on Clifford, see (Nickerson and Griffin 2008). If Russell's (1897) argument worked, it would banish both Wellsian and Gödelian travel a priori but without invoking either the 'Grandfather Paradox' or 'causal loop' objections definitively defused in Lewis (1976).
} 

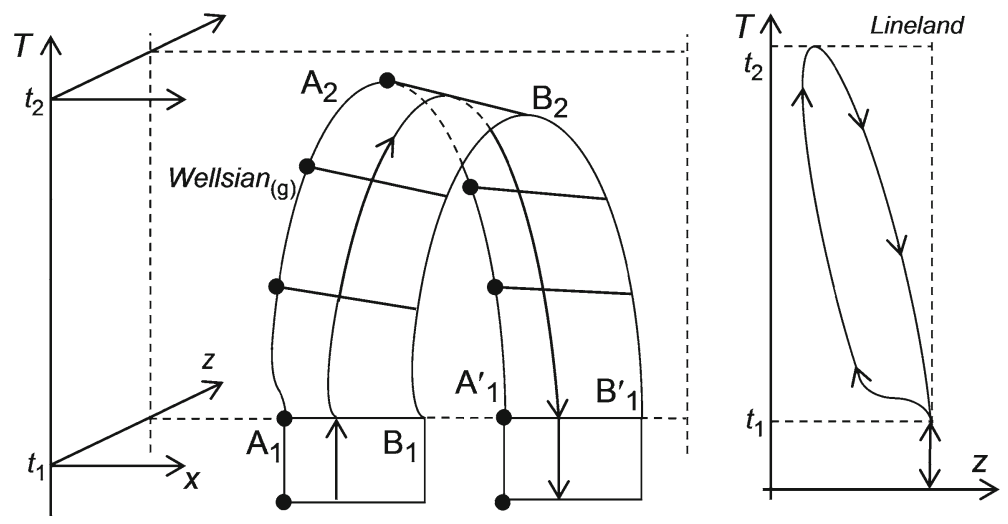

Fig. 9 Topological looping

Points $\mathrm{A}_{1}, \mathrm{~B}_{1}, \mathrm{~A}_{1}^{\prime}$ and $\mathrm{B}_{1}^{\prime}$ all lie in Lineland. Extremities $\mathrm{A}$ and $\mathrm{B}$ intersect $t_{1}$ at $\mathrm{A}_{1}$ and $\mathrm{B}_{1}$ when Wellsian $(\mathrm{g})$ travels forward in time and at $\mathrm{A}_{1}^{\prime}$ and $\mathrm{B}_{1}^{\prime}$ when Wellsian $(\mathrm{g})$ travels backward. $\mathrm{A}_{2}$ and $\mathrm{B}_{2}$ are where extremities $\mathrm{A}$ and $\mathrm{B}$ lie at $t_{2}$, i.e. the instant when Wellsian $_{(\mathrm{g})}$ proceeds neither forward nor backward in time. A occupies $\mathrm{A}_{1}$, $\mathrm{A}_{2}$ and $\mathrm{A}_{1}^{\prime}$ in that personal order; $\mathrm{B}$ occupies $\mathrm{B}_{1}, \mathrm{~B}_{2}$ and $\mathrm{B}_{1}^{\prime}$ in that personal order. Wellsian $_{(\mathrm{g})}$ effectively leaves Lineland at $t_{1}$ then loops back to re-join Lineland at $t_{1}$ in another place.

Wellsian $_{(\mathrm{g})}$ escapes both stage-overlap and Cheshire Cat fades but never changes chirality or leaves its local linear space. (Figure 9 shows two space dimensions but Wellsian $_{(\mathrm{g})}$ stays in its local linear space throughout.) Wellsian $(\mathrm{g})$ need not even move, but can merely persist forward $t_{1}$-to- $t_{2}$, and backward $t_{2}$-to- $t_{1}$. Given correct topology (plus ability to move back in time), Wellsian $(\mathrm{g})$ presents no dynamic, spatial or biological difficulties. Figure 9 loop is only spatial - external time increases $t_{1}$-to- $t_{2}$ along both arms. What happens at $t_{2}$ ? In external time, the loop ceases to exist or runs out of space.

Wellsian $_{(\mathrm{g})}$ 's loop only exists for finite external time $t_{1}$-to- $t_{2}$, and only twice that interval of personal time (i.e. $t_{1}$-to- $t_{2}$ then $t_{2}$-to- $t_{1}$ ). Wellsian $(\mathrm{g})$ 's reversal needs precise timing: if reversal begins (externally) before $t_{2}$, Wellsian $(\mathrm{g})$ double-occupies; however, reversal later than $t_{2}$ is impossible because the loop doesn't exist (externally) later than $t_{2}$. If entered by an object unable to reverse temporal direction, the loop is a blind alley.

The need for 'loops' confines Wellsian travel to spaces where topologically-suitable connections exist naturally or can be made. Newtonian space is independent of matter. It affects matter (e.g. dictating matter's degrees of movement) but cannot be affected by it. Newtonian space is multiply hostile to topological-rotation Wellsian travel. Tridimensionality is neither necessary nor sufficient for space being Newtonian. However, Newtonian space is essentially time/matter-independent and flat. (See e.g. Maudlin 1993.) Rotating Wellsians require either flat $(n+)$-dimensional space or curved $n$-dimensional space. Varying curvature needs non-uniform space; creating curvature needs mutable space. If space cannot be curved to order, Wellsian travel needs pre-existing spatial curvatures. Wells' (1895) Traveler can go anywhere in his- 
tory; Cliffordian Wellsians are restricted by available spatial curvatures and so stand to space rather as Gödelians do to spacetime.

Clifford's time-evolving, locally-curved space remains Newtonian qua being absolute, unaffectable by matter and substantival. Letting space and matter-distribution interact reciprocally comes closer to general relativity. Call matter-affectable, locallycurved, absolute space 'neo-Cliffordian'. Neo-Cliffordian spaces allow the local topological (e.g. 'loop') connections requisite for survivable reversals. Such spaces can also remain time-independent substances even if their structures vary over time. (Neo-)Cliffordian time can remain Newtonian, i.e. uniform, independent of space and matter, unaffectable by matter and (crucially) possessing global timeslices.

Controllable Wellsian travel needs plastic neo-Cliffordian spatial structure. Such permits topological connections that let travelers rotate relative to global space but retain constant orientation relative to their local space. This in turn requires suitablylarge (and enduring) curved regions that join smoothly to otherwise uniform space. Given natural correctly-configured regions, Cliffordian universes could permit Wellsian travel even if spatial structure was immune from human control. Admittedly such regions would need to be comparatively common, accommodating and easy to locate if Wellsian travel were to be easy, frequent or regular. Also, even given free ingress/egress to topologically-suitable regions, some additional mechanism seems required for triggering Wellsians' temporal reversals. If such 'looped' regions temporally reverse their contents automatically, the process risks being involuntary (if not de facto Gödelian) and restricted. In contrast, Wells' (1895) Traveler can theoretically visit all time and space.

An electrostatic puzzle remains to be addressed. If Wheeler-Feynman backwardmatter is antimatter, what prevents even neo-Cliffordian Wellsians suffering mutual annihilation when their phases connect? Perhaps any requisite 'warping' should also affect local time-direction, so rotating Wellsians hold constant orientation relative to local space and time. But if warping means travelers also share time's local (i.e. not global) direction, any resulting travel is Gödelian, i.e. not Wellsian at all. However, phases of hyper-rotating Wellsians meet only as unextended objects at instants and not as extended objects over extended times. The mutual annihilation problem vanishes if 'at-at' temporal direction theories mean objects are strictly chargeless at any instant, apex or otherwise. So 'at-at' temporal directionality means reversing Wellsians need not become anti-matter, while neo-Cliffordian travel dissolves double occupancy.

\section{Conclusions}

Although such was perhaps not their aim, Grey (1999), Le Poidevin (2005) show continuous, controllable and survivable backward Wellsian travel can't occur in strictly Newtonian space. Newtonian spaces threaten time travelers with metaphysical, physical and biological challenges, including discontinuities, co-occupancy, Cheshire Cats, chimeras, singularities and fluid-loss. These problems are no respecters of sizeWellsian atoms face discontinuity/co-occupancy dilemmas as much as humans.

Some problems (e.g. discontinuity and co-occupancy) are mutually exclusive but solving some generates others, (e.g. Cheshire Cat fades as solutions to co-occupancy). 
However, pace Grey (1999), Le Poidevin (2005), extended Wellsians can reverse temporal direction, granted space has extra dimensions or (preferably) variable topology. Wellsians fare best in warped space but do not require Gödelian 'warped' time. Hence even if Gödel travel is not time travel, absolute time need not forbid time travel.

So time travel can occur even if Gödel travel is either impossible or not true time travel. Physical objects can reverse in Newtonian time. While Clifford (1886) suggests some spatial resources for Wellsians, Wellsians' best bet are flexible 'neo-Cliffordian' worlds. In such worlds, time and space remain separate substances yet matter and space can reciprocally affect each other and create local topological identifications. Unlike Newtonian space, Wellsian (neo-Cliffordian) space must be mutable and curved. Hence Newtonian space poses greater hazards for aspirant Wellsians than Newtonian time. To enjoy unrestricted time-travel, Wellsians must be able to change space itself.

Acknowledgements Many thanks to two anonymous Synthese referees for helpful comments on earlier drafts of this paper. Many thanks too to my 'Philosophy of Time Travel' students over the years for entertaining and informative discussions - in particular Cat Mcdonald-Wade, Emily Paul and Vivek Santayana. A special mention too to Oliver Lunel for the 'cryogenics' suggestion. I first encountered the idea of rotating a three-dimensional time traveler through four-dimensional space in Grant Morrison's The Invisibles, (New York: Vertigo/D.C. Comics, 1994-2000)

Open Access This article is distributed under the terms of the Creative Commons Attribution 4.0 International License (http://creativecommons.org/licenses/by/4.0/), which permits unrestricted use, distribution, and reproduction in any medium, provided you give appropriate credit to the original author(s) and the source, provide a link to the Creative Commons license, and indicate if changes were made.

\section{References}

Abbott, A. (1884). Flatland: A romance of many dimensions. Cambridge: Cambridge University Press.

Barrow, J. D., \& Dąbrowski, M. P. (1998). Gödel universes in string theory. Physical Review D, 58, 1-5.

Bernstein, S. (2015). Nowhere man: Time travel and spatial location. Midwest Studies in Philosophy, 39, $158-168$.

Bourne, C. (2006). A future for presentism. Oxford: Oxford University Press.

Clifford, W. (1886). The common sense of the exact sciences. London: Kegan Paul. Ed. Karl Pearson.

Dowe, P. (2000). The case for time travel. Philosophy, 75, 441-451.

Earman, J. (1995). Bangs, crunches, whimpers and shrieks, singularities and acausalities in relativistic spacetimes. Oxford: Oxford University Press.

Feynman, R. (1949). The theory of positrons. Physical Review, 76, 749-759.

Geduld, H. (1987). The definitive time machine: A critical edition of $H$. G. Wells's scientific romance with introduction and notes. Bloomington: Indiana University Press.

Gibbard, A. (1975). Contingent identity. Journal of Philosophical Logic, 1975, 187-221.

Gödel, K. (1949). An example of a new type of cosmological solutions of Einstein's field equations of gravitation. Reviews of Modern Physics, 21, 447-450.

Grey, W. (1999). Troubles with time travel. Philosophy, 74, 55-70.

Le Poidevin, R. (2005). The Cheshire Cat problem and other spatial obstacles to backwards time travel. The Monist, 88, 336-352.

Lewis, D. (1976). The paradoxes of time travel. American Philosophical Quarterly, 13, 145-152.

Lewis, D. (1986). On the plurality of worlds. Oxford: Blackwell.

Lindgren, W., \& Banchoff, T. (2010). Flatland by Edwin A. Abbott: An edition with notes and commentary. Cambridge: Cambridge University Press.

Lofting, H. (1920). The story of Doctor Dolittle. London: Frederick A. Stokes.

Maudlin, T. (1993). Buckets of water and waves of space: Why space-time is (probably) a substance. Philosophy of Science, 27, 183-203. 
Michell, J. (1784). On the means of discovering the distance, magnitude, \&c. of the fixed stars, in consequence of the diminution of the velocity of their light. Philosophical Transactions of the Royal Society of London, 74, 35-57.

Nickerson, S., \& Griffin, N. (2008). Russell, Clifford, Whitehead and differential geometry. Russell: The Journal of Bertrand Russell Studies, 28, 20-38.

Pfarr, J. (1981). Time travel in Gödel space. General Relativity and Gravitation, 13, 1073-1091.

Richmond, A. (2000). Plattner's arrow: Science and multi-dimensional time. Ratio, 13, 256-274.

Rucker, R. (1986). The fourth dimension, and how to get there. Harmondsworth: Penguin.

Russell, B. (1897). An essay on the foundations of geometry. Reprinted 1996. London: Routledge.

Russell, B. (1959). My philosophical development. Reprinted 1997. London: Routledge.

Torretti, R. (1999). Relativity, time reckoning and time series. In J. Butterfield (Ed.), The arguments of time (pp. 65-82). Oxford: Oxford University Press.

van Cleve, J. (1987). Right, left, and the fourth dimension. The Philosophical Review, 96, 33-68.

Wells, H. G. (1894). The national observer time machine. In Harry M. Geduld (Ed.), The definitive time machine (pp. 154-174). Bloomington: Indiana University Press.

Well, H. G. (1895). The time machine. London: Heinemann. (cited here from Geduld (1987)).

Wells, H. G. (1896). The plattner story. The complete short stories of H. G. Wells. London: Ernest Benn Ltd.

Whitrow, G. J. (1955). Why physical space has three dimensions. The Brittish Journal of Philosophical Science, 6, 13-31.

Yourgrau, P. (1999). Gödel meets Einstein. La Salle: Open Court. 